\title{
Pythium induced phenolic compounds in the resistance of Vitis vinifera to Botrytis cinerea
}

\author{
Bala $\mathbf{K}^{1^{*}}$ and Paul $\mathbf{B}^{2}$ \\ ${ }^{1}$ Forensic Science, Trent University, 1600 West Bank Drive, Peterborough, Ontario K9J7B8, Canada \\ ${ }^{2}$ Laboratoire de Mycologie et Phytopathologie, Institut Jules Guyot, Université de Bourgogne, Dijon 21000, France
}

Bala K, Paul B 2012 - Pythium induced phenolic compounds in the resistance of Vitis vinifera to Botrytis cinerea. Plant Pathology \& Quarantine 2(1), 16-23, doi 10.5943/ppq/2/1/3/

Grey mold rot in grapevine is caused by a necrotrophic pathogen, Botrytis cinerea. There is an enormous loss in the quality and quantity of grapes in the Burgundian vineyards due to Botrytis infection. Our studies demonstrate that some species of Pythium are capable of inducing disease resistance in grapevine against the grey mold pathogen by accumulating phenolic compounds notably, ellagic, caffeic, gallic, caffeic, o-anisic, 3,4-dihydroxy benzoic and salicyclic acid. This is the first report on Pythium induced accumulation of phenolic compounds in the grapevine challenged by $B$. cinerea. Phenolic compounds produced in grapevine at different time periods after exposure to Pythium and $B$. cinerea were quantified and their significant increase in quantity was evaluated by statistical analyses.

Key words - Botrytis cinerea - disease resistance - HPLC - oomycete - phenolic compounds Pythium - Vitis vinifera

\author{
Article Information \\ Received 22 February 2012 \\ Accepted 28 February 2012 \\ Published online 14 March 2012 \\ *Corresponding author: Kanak Bala - e-mail - kanak.bala@gmail.com
}

\section{Introduction}

Botrytis cinerea is a necrotrophic pathogen that infects a wide variety of plants such as tomato, beans, peppers, strawberries, onion and other crop plants (Elad \& Shtienberg 1995). B. cinerea has ability to survive harsh environmental conditions in the form of sclerotia. The emergence of fungicide resistant strains of B. cinerea (Katan 1982) is challenging for the grape growers. There is an estimated $15-40 \%$ annual loss in grapevine due to grey mold disease in France.

Pythium is a diverse genus that consists of approximately 140 recognized saprobic and parasitic species. The plant parasitic species of Pythium have devastating impact on economically important crops worldwide (Vanterpool 1938). Some Pythium spp. are aggressive mycoparasites of B. cinerea (Paul 1999) and non-pathogenic to tomato, beans (Bala et al. 2009) and grapevine.

In the past few decades, phenolic acids have received major attention as antifungal factors in biological control (Lavania et al. 2006). The role of phenolic acids in the defense against bacterial and fungal infections has been demonstrated (Harborne 1993, Ebukanson 1989). Although phenolic acids are known to be present in plants (Hendry 1993), their accumulation is increased under biotic or abiotic stress. This increased production is possibly related to enhanced disease resistance in plants against pathogens (Lattanzio et al. 2006).

Major phenolic compounds like gallic, caffeic, ellagic, ferulic, chlorogenic, protocatechuic acids were induced by Serratia marces- 
cens NBRI1213 in betelvine roots and shoots challenged with Phytophthora nicotianae (Lavania et al. 2006). Phenolic acids have antifungal properties (Sharma \& Singh 2003) that confer protection to plants against fungal infections. Phenolic compounds lacking antifungal activity, such as gallic acid, get converted into antifungal compounds that are gallotannins and thereby protect plants against fungal infections (Binutu \& Cordell 2000).

Phenolic acids are well known to have key role in the cell wall lignification and phytoalexin synthesis (Wagner 1988). Phenolic acids, particularly coumaric acid, caffeic and ferulic acid are intermediates of lignin biosynthesis (Dixon \& Paiva 1995). Lignin accumulation is associated with an increase in cell-wall mechanical rigidity thereby preventing invasion of xylem (Stafford 1988). Lignin and phytoalexin accumulation provides resistance to plants against pathogens. Other phenolic compounds, especially synthetic caffeic acid and rosmarinic acid have a direct inhibitory effect on the germination of zoospores of Phytophthora capsici, P. megakarya and $P$. palmivora (Wid-mer \& Laurent 2006).

The most important signaling molecule, salicyclic acid (SA), is the key compound in local and systemic disease resistance (MauchMani \& Slusrenko 1996, Shah \& Klessig 1999) and synthesis of pathogenesis related protein (PR) (Dempsey et al. 1999; Shah \& Klessig 1999). Systemic acquired resistance (SAR) is induced by the exposure of root or foliar tissues to abiotic or biotic elicitors and is dependent on the phytohormone salicylate that is associated with the accumulation of pathogenesis related proteins. An activated PR expression restricts infection by pathogens and therefore, the transgenic plants that were not able to accumulate salicyclic acid could not activate SAR genes or disease resistance to an array of pathogens that they encountered (Ward et al. 1991, Gaffney et al. 1993).

Our objectives are to assess the synthesis of phenolics in grapevine coinoculated with Pythium and Botrytis and to compare their quantity in grapevine inoculated with different species of Pythium. We provide the first evidence for Pythium-induced increase in the accumulation of phenolic compounds in grapevine leaves during ongoing suppression of B. cinerea by Pythium spp.

\section{Methods}

\section{Pythium isolation}

Pythium species were isolated from soil using hemp-seed baiting technique (Bala et al. 2006). The name of isolates used in this study and their GenBank accession numbers are provided in Table 1.

\section{Growth in culture and inoculations of in vitro grapevine plants}

Pythium isolates were grown and maintained on potato carrot agar (PCA), corn meal agar (CMA) and potato dextrose agar (PDA). PCA was prepared by boiling $20 \mathrm{~g}$ of carrots and $20 \mathrm{~g}$ of potato in 1 litre of distilled water followed by adding $15 \mathrm{~g}$ of agar (Difco) to the extract and sterilization for $20 \mathrm{~min}$ by autoclaving. CMA (Difco) and PDA (Difco) were prepared according to the manufacturer instructions. Botrytis cinerea strains were isolated from grapes in the vineyards of Marsannay-la-Côte region that is located $6 \mathrm{~km}$ South-West of Dijon. B. cinerea strain BC-3 cultures were grown on PDA. Murashige and Skoog media (Murashige \& Skoog 1962) was prepared, sterilized and inoculated with the sterile grapevine varieties pinot noir and chardonnay twigs and transferred to growth chamber maintained at $24^{\circ} \mathrm{C}$ with $16 \mathrm{~h}$ light and $8 \mathrm{~h}$ dark photoperiod. Three months old in vitro grapevine cultivar chardonnay leaves were inoculated with the Pythium spp. only, or Pythium spp. and B. cinerea simultaneously. The leaves were collected every 24 hours for 3 consecutive days.

\section{Extraction method for phenolics and HPLC analysis}

The grapevine leaves were vacuumdried and the dry weight of leaves was measured. Salicyclic acid and other phenolics were extracted from $10 \mathrm{mg}$ of grapevine leaves using methods of Verberne et al. (2002). Analysis of polyphenol content was done using RP-HPLCDAD/FD (Reverse Phase High Performance Liquid Chromatography coupled to Diode Array Detector and Fluorescence Detector). 
Phenolic compounds were analysed with a Dionex Summit system (Sunnyvale, CA, USA) equipped with a P580 gradient pump, a GINA 50 autosampler, a UVD 340S diode array detector (DAD), a JASCO FP-920 Intelligent Fluorescence Detector and an external BIO-RAD column heater. The separation was performed with a Nucleodur (Macherey-Nagel, Germany) RP C-18 Pyramid ( 250 x $4.6 \mathrm{~mm}$ i.d; $5 \mu \mathrm{m}$ particle size) operated at a temperature of $40^{\circ} \mathrm{C}$. The mobile phase consisted of $0.1 \%$ TFA in water (eluent A) and $0.075 \%$ TFA in acetonitrile (eluent B). The gradient program was as follows: $0 \% \mathrm{~B}$ to $9 \% \mathrm{~B}$ (15 min), 9\% B to $18 \% \mathrm{~B}(50 \mathrm{~min}), 18 \% \mathrm{~B}$ to $100 \% \mathrm{~B}(10 \mathrm{~min})$, $100 \% \mathrm{~B}(5 \mathrm{~min}), 100 \% \mathrm{~B}$ to $0 \% \mathrm{~B}(5 \mathrm{~min})$ and column equilibration at $100 \%$ A during $5 \mathrm{~min}$. Total run time was $90 \mathrm{~min}$. The injection volume for all samples was $10 \mu \mathrm{L}$.

Simultaneous monitoring was set at 308 $\mathrm{nm}$ (p-coumaric acid, ferulic acid, caffeic acid, o-anisic acid and salicylic acid), $254 \mathrm{~nm}$ (ellagic acid, rutin, morin, quercetin-3-beta glucoside), $360 \mathrm{~nm}$ (quercetin, myricetin, kaempferol), $280 \mathrm{~nm}$ (gallic acid, catechin, epicatechin) for the DAD and excitation and emission wavelengths were set at $300 \mathrm{~nm}$ and $374 \mathrm{~nm}$ (specific wavelengths for stilbenes family molecules: trans-resveratrol, transpiceid, trans-pterostilbene and trans-4-hydroxystilbene) respectively for the fluorescence detection, at a flow-rate of $1.0 \mathrm{~mL} / \mathrm{min}$. Spectra were recorded from 200-595 nm. Phenolic compounds were identified by HPLC by their retention and spectral data as compared by standards and were quantified using six-points calibration curves with custom-made external standard solutions (Sigma-Aldrich Chemical Company) from $1 \mathrm{mg} / \mathrm{L}$ to $0.1 \mathrm{mg} / \mathrm{L}$ and every 10 injections, a check standard solution was used to confirm the calibration of the system.

\section{Statistical evaluation}

All experiments were repeated three times, with three replications for each sample. The presented values are the means of nine determinations \pm SD. Statistically significant differences in the mean values were analyzed by two-way ANOVA. Tukey's-test was performed to test the significance in mean differences at $\mathrm{p}<0.05$.

\section{Results}

Total phenolic contents Figs 1-6

The total quantity of phenolic compounds accumulated in the grapevine leaves were measured by HPLC analysis. The quantities and other details are provided in Table 1 . There was a significant difference ( $\mathrm{p}<$ 0.05 ) in the total phenolic acid content in grapevine leaves exposed to different Pythium spp. as assessed by two-way ANOVA. The highest phenolics content was observed at $72 \mathrm{~h}$ of post inoculation with Pythium and Botrytis. The phenolic compounds accumulated were mostly 3,4-dihydroxy benzoic acid, caffeic acid, gallic acid, ellagic acid, o-anisic acid and salicyclic acid. Among these, ellagic acid was produced in the highest concentration. The content was significantly different in other species of Pythium. The other phenolic acid contents were significantly lower than ellagic acid. The phenolic content increased with time and varied depending on the species of Pythium used for inoculation. The quantity of phenolics was significantly higher $(\mathrm{p}<0.05)$ when strains of $P$. ultimum were used for the treatments. The species used in this analysis were non-pathogenic to grapevine and most of these were robust mycoparasites of Botrytis cinerea.

The maximally accumulated phenolic compounds in the grapevine leaves were ellagic acid (245 $\mu \mathrm{g} / \mathrm{ml}$ dry weight), 3,4dihydroxy benzoic acid $(882 \mu \mathrm{g} / \mathrm{ml}$ dry weight), o-anisic acid ( $80 \mu \mathrm{g} / \mathrm{ml}$ dry weight), caffeic $(6 \mu \mathrm{g} / \mathrm{ml}$ dry weight), gallic $(1 \mu \mathrm{g} / \mathrm{ml}$ dry weight) and salicylic acid $(0.4 \mu \mathrm{g} / \mathrm{ml}$ dry weight). The caffeic, gallic and salicyclic acid were produced in relatively lower amounts (Table 1). The quantities of all the phenolics amassed in the controls were negligible. The grapevines leaves challenged with Botrytis and treated with Pythium were many-fold higher in phenolics content than those treated with Pythium alone.

The enhanced accumulation of phenolic acids in grapevine challenged with $B$. cinerea and exposed to Pythium spp. demonstrates the possible role of phenolic compounds in inducing disease resistance in grapevine. The phenolic acids have an antifungal property that 
Table 1 Phenolic acids content in grapevine leaves after co-inoculation with $B$. cinerea and Pythium species.

\begin{tabular}{|c|c|c|c|c|c|}
\hline Phenolic compounds & Formula & Biological effects & $\begin{array}{l}\text { Maximum } \\
\text { quantity } \\
(\mu \mathrm{g} / \mathrm{ml})\end{array}$ & $\begin{array}{l}\text { Pythium spp. used } \\
\text { in this study }\end{array}$ & $\begin{array}{l}\text { GenBank } \\
\text { Accessions }\end{array}$ \\
\hline Ellagic acid & & $\begin{array}{l}\text { antioxidant and } \\
\text { antiproliferative }\end{array}$ & 245 & $\begin{array}{l}P . \text { ultimum strain F- } \\
1313, P . \text { ultimum } \\
\text { strain KN-27, } P . \\
\text { paroecandrum } \\
\text { strain B-30, } P . \\
\text { longisporangium } \\
\text { strain B76a, } P . \\
\text { rhizooryzae strain } \\
\text { F-1243 }\end{array}$ & $\begin{array}{l}\text { AY737318, } \\
\text { AF215686, } \\
\text { AY150168.1, } \\
\text { AY455804.1, } \\
\text { AY207379 }\end{array}$ \\
\hline Caffeic acid & & $\begin{array}{l}\text { antioxidant and } \\
\text { anticancer }\end{array}$ & 6 & \multirow{5}{*}{$\begin{array}{l}\text { P. ultimum strain F- } \\
\text { 1313, P. ultimum } \\
\text { strain KN-27 }\end{array}$} & \multirow{5}{*}{$\begin{array}{l}\text { AY737318, } \\
\text { AF215686 }\end{array}$} \\
\hline Gallic acid & & \begin{tabular}{|l|} 
anti-cancer, anti- \\
inflammatory and anti- \\
neural disorders
\end{tabular} & 1 & & \\
\hline o-Anisic acid & & $\begin{array}{l}\text { Constituent of } \\
\text { antiseptic compounds }\end{array}$ & 80 & & \\
\hline $\begin{array}{l}\text { 3,4-Dihydroxy } \\
\text { benzoic acid } \\
\text { (protocatechuic acid) }\end{array}$ & & $\begin{array}{l}\text { Antigenotoxic effect } \\
\text { and tumoricidal activity }\end{array}$ & 882 & & \\
\hline Salicylic acid & & Prevents skin diseases & 0.4 & & \\
\hline
\end{tabular}

confers resistance to grapevine against the grey mold pathogen.

This study provides first evidence on the role of Pythium as a biological elicitor that induces defense system in plants via production of phenolics in grapevine.

The phenolic compounds showed significant differences in their amounts depending on the species and time after application. Salicylic acid was only reported in Vitis vinifera cultivar chardonnay and not detected in cultivar pinot noir. Total phenolic acids amount in grapevine shows significant increase at $24 \mathrm{~h}, 48 \mathrm{~h}$ and attains a maximum level at $72 \mathrm{~h}$ of post inoculation. The in-vitro plants treated with both Pythium spp. and $B$. cinerea showed a large increase over those treated with Pythium spp. only. The leaves coinoculated with the Pythium spp. and $B$. cinerea did not show any grey mold symptoms supporting the direct mycoparasitic action of Pythium on Botrytis. The leaves treated only with $B$. cinerea exhibited severe necrotic lesions within a week.

\section{Discussion}

The importance of phenolics in health and disease control has been described by Larrosa et al. 2010. Some of these phenolic compounds occur naturally in fruits and vegetables. Ellagic acid is naturally present in berries such as raspberries, cranberries, grapes, pomegranates and has antioxidant and antiproliferative properties (Umesalma \& Sudhandiran 2011). Therefore, the consumption of ellagic acid has increased recently considering the health benefits. Our results strongly demonstrate that in the presence of Pythium, the grapevine resists the growth of $B$. cinerea and begets phenolics. Ellagic acid is synthesized in the highest quantities among all other phenolics in the grapevine leaves (Fig. 1).

Caffeic acid has potential antioxidant and anticancer properties. It occurs naturally in many fruits and vegetables such as cucumber and grapes. It is known to prevent skin irritation, eye swelling, sunburn and dermatitis (Li et al. 2005). Our studies showed that there is an ample increase in the amount of caffeic 

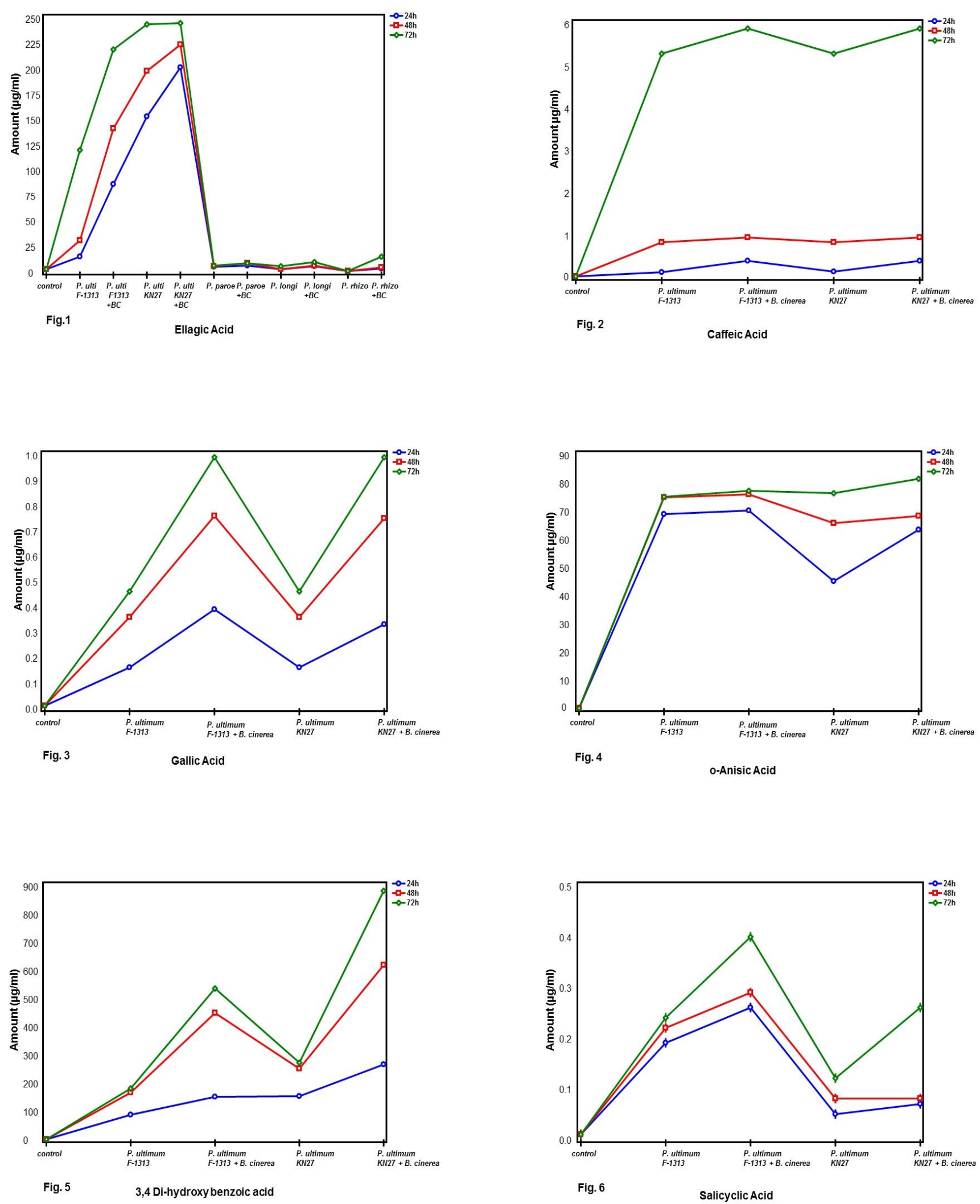

Figs 1-6 - Phenolic acid contents in grapevine leaves treated with Pythium spp. and co-culture of Pythium spp. and Botrytis cinerea. Control represents non-treated grapevine leaf. 1 Ellagic acid content. 2 Caffeic acid. 3 Gallic acid. 4 o-Anisic acid. 5 3,4-Dihydroxybenzoic acid. 6 Salicyclic acid. Abbreviations: $B C=$ Botrytis cinerea, $P$. longi $=P$. longisporangium, $P$. paroe $=P$. paroecandrum, $P$. rhizo $=P$. rhizooryzae, $P$. ulti $=P$. ultimum. 
acid when Pythium is counteracting B. cinerea on grapevine leaves (Fig. 2).

Gallic acid also known as 3, 4, 5 trihydroxy benzoic acid is naturally found in gallnut, sumac, witch hazel, tea leaves and other plants. Previous studies (Kim etal 2011) have shown that it has anti-inflammatory, antineural disorders activities and anti-cancer activities against leukemia, certain prostrate, colon and lung cancer cells. Our results show that gallic acid is detected in the grapevine leaves during an ongoing interaction between Pythium and B. cinerea (Fig. 3). Anisic acids are considered to be parts of antiseptic compounds. The synthesis of o-anisic acid (Figure 2) is observed in grapevine leaves treated with Pythium and B. cinerea (Fig. 4).

3,4 Di-hydroxy benzoic acid (DHBA) also known as protocatechuic acid has antigentoxic and tumoricidal effects on leukemia cells (Tanaka et al. 2011). Our analysis shows an enhanced production of DHBA when Pythium mycoparasitises Botrytis on grapevine leaves (Fig. 5).

Salicyclic acid has dual benefits, both cosmetic and medicinal, and is used to treat skin diseases, acne, psoriasis and remove warts (Paterson \& Lawrence 2001). It is used in the form of aspirin to treat fevers and to prevent pain, clots and cardiac disease. Salicylic acid is also known to mediate systemic acquired resistance (SAR) and induce host defenses during pathogen infection on plants (Métraux et al. 1990). Our analysis sheds light on its induction in grapevine (Fig. 6) by Pythium in the process to suppress $B$. cinerea and its possible involvement in the activation of disease resistance.

Phenolic compounds with antioxidant and anti-proliferation activities help in prevention and treatment of cancer (Grassmann et al. 2002). Hence, consumption of fruits with increased phenolics content could have potential health benefits. The grapes treated with biological agents should be investigated for phenolics composition and should be explored for medicinal purposes. Grapevine leaves that are thrown away instead should be studied for usefulness in nutritional, health benefits and disease cure. Consumption of biologically treated grapevine and improved quality wine might have beneficial human health effects. Content of antioxidant compounds in chemically and biologically treated wine could be measured for further validation. Further research on medicinal aspects will elaborate more applications in human health benefits.

Thus, we conclude that with the application of Pythium spp., it is possible to induce the synthesis of phenolic compounds in grapevine that are believed to have a role in disease resistance and control of the pathogen, B. cinerea. The synthesis of phenolic compounds is possibly correlated with the activation of pathogenicity resistance (PR) genes in grapevine that further inhibits infection by $B$. cinerea. Molecular study on pathogenesis at gene level will uncover the genes involved in the resistance mechanisms.

Moreover, investigating underlying molecular mechanisms in induced resistance will open new windows for disease control and crop biosecurity.

\section{Acknowledgements}

This work was a part of doctoral research of first author at the Universite de Bourgogne, Dijon, France. The authors thank Prof. Lucien Hoffmann and Dr. Daniele Evers at the CRP-Gabriel Lippmann Institute, Belvaux, Luxembourg for providing the laboratory facilities. We thank Dr. Mouhssin Oufir at Gabriel Lippmann Institute for his technical assistance in HPLC.

\section{References}

Bala K, Gautam N, Paul B. 2006 - Pythium rhizo-oryzae sp. nov. isolated from paddy fields: taxonomy, ITS Region of rDNA, and comparison with related species. Current Microbiology 52, 102107.

Bala K, David DR, Paul B, Elad Y. 2009 Pythium elicitors in biological control of Botrytis cinerea. IOBC/Wprs Bulletin 42, 11-14.

Binutu OA, Cordell GA. 2000 - Gallic acid derivatives from mezoneuron benthamianum leaves. Pharmaceutical Biology 38, 284-286.

Dempsey DA, Shah J, Klessig DF. 1999 Salicylic acid and disease resistance in 
plants. Critical Reviews in Plant Sciences 18, 547-575.

Dixon RA, Paiva NL. 1995 - Stress-induced phenylpropanoid metabolism. The Plant Cell 7, 1085-1097.

Ebukanson GJ. 1989 - Relation of phenolic acid to soft-rot disease resistance in yam tubers in Nigeria. Letters in Applied Microbiology 9, 185-186.

Elad Y, Shtienberg D. 1995 - Botrytis cinerea in greenhouse vegetables: chemical, cultural, physiological and biological controls and their integration. Integrated Pest Management Reviews 1, 15-29. Gaffney T, Friedrich L, Vernooij B, Negrotto D, Nye G, Uknes S, Ward E, Kessmann H, Ryals J. 1993 - Requirement of salicylic acid for the induction of systemic acquired resistance. Science 261, 754-756.

Grassmann J, Hippeli S, Elstner EF. 2002 Plant's defence and its benefits for animals and medicine: role of phenolics and terpenoids in avoiding oxygen stress. Plant Physiology and biochemistry 40, 471-478.

Harborne JB. 1993 - Introduction to ecological biochemistry Academic Press, London.

Hendry GAF, 1993 - Methods in comparative plant ecology: A laboratory manual. Chapman \& Hall, London, pp. 180-181.

Katan T. 1982 - Resistance to 3,5-dichlorophenyl-N-cyclic imide ('dicarboximide') fungicides in the grey mould pathogen Botrytis cinerea on protected crops. Plant Pathology 31, 133-141.

Kim MJ, Seong AR, Yoo JY, Jin CH, Lee YH, Kim YJ, Lee J, Jun WJ, Yoon HG. 2011 - Gallic acid, a histone acetyltransferase inhibitor, suppresses betaamyloid neurotoxicity by inhibiting microglial-mediated neuroinflammation. Molecular Nutrition and Food Research 55, 1798-1808.

Larrosa M, Garcia-Conesa MT, Espin JC, Tomas-Barberan FA. 2010 - Ellagitannins, ellagic acid and vascular health. Molecular Aspects of Medicine 31, 513-539.

Lattanzio V, Lattanzio VMT, Cardinali A, 2006 - Role of phenolics in the resistance mechanisms of plants against fungal pathogens and insects. In: Phytochemistry Advances in Research. India: Research Signpost, pp. 23-67.

Lavania M, Chauhan PS, Chauhan SV, Singh HB, Nautiyal CS. 2006 - Induction of plant defense enzymes and phenolics by treatment with plant growth-promoting rhizobacteria Serratia marcescens NBRI1213. Current Microbiology 52, 363-8.

Li PG, Xu JW, Ikeda K, Kobayakawa A, Kayano Y, Mitani T, Ikami T, Yamori Y. 2005 - Caffeic acid inhibits vascular smooth muscle cell proliferation induced by angiotensin II in strokeprone spontaneously hypertensive rats. Hypertension Research 28, 369-77.

Mauch-Mani B, Slusrenko AJ. 1996 Production of salicylic acid precursors is a major function of phenylalanine ammonia-lyase in the resistance of Arabidopsis to Peronospora parasitica. The Plant Cell 8, 203-212.

Métraux JP, Signer H, Ryals J, Ward E, WyssBenz M, Gaudin J, Raschdorf K, Schmid E, Blum W, Inverardi B. 1990 - Increase in salicylic acid at the onset of systemic acquired resistance in cucumber. Science 250, 1004-1006.

Murashige T, Skoog F. 1962 - A revised medium for rapid growth and bioassays with tobacco cultures. Physiology Plantarum 15, 473-497.

Paterson JR, Lawrence JR. 2001 - Salicylic acid: a link between aspirin, diet and the prevention of colorectal cancer. QJM : An International Journal of Medicine 94, 445-448.

Paul B. 1999 - Suppression of Botrytis cinerea causing the grey mould disease of grapevine by an aggressive mycoparasite, Pythium radiosum. FEMS Microbiology Letters 176, 25-30.

Shah J, Klessig DF. 1999 -Signal perception and transduction. Biochemistry and Molecular Biology of Plant Hormones, Oxford, Elsevier.

Sharma BK, Singh UP. 2003 - Ferulic acid may prevent infection of Cicer arietinum by Sclerotium rolfsii. World Journal of Microbiology and Biotechn- 
ology 19, 123-127.

Stafford NA. 1988 - Proanthocyanidins and the lignin connection. Phytochemistry 27, 1-6.

Tanaka T, Tanaka T, Tanaka M. 2011 Potential cancer chemopreventive activity of protocatechuic acid. Journal of Experimental and Clinical Medicine 3, 27-33.

Umesalma S, Sudhandiran G. 2011 - Ellagic acid prevents rat colon carcinogenesis induced by 1, 2 dimethyl hydrazine through inhibition of AKT-phosphoinositide-3 kinase pathway. European Journal of Pharmacology 660, 249-258.

Vanterpool TC. 1938 - Some species of Pythium parasitic on wheat in Canada and England. Annals of Applied Biology 25, 528-543.

Verberne MC, Brouwer N, Delbianco F,
Linthorst HJ, Bol JF, Verpoorte R. 2002 - Method for the extraction of the volatile compound salicylic acid from tobacco leaf material. Phytochemical Analysis 13, 45-50.

Wagner MR, 1988 - Induced defenses in ponderosa pine against defoliating insects Mechanism of woody plant defenses against insects. New York, Springer, pp. 141-155.

Ward ER, Uknes SJ, Williams SC, Dincher SS, Wiederhold DL. 1991 - Coordinate gene activity in response to agents that induce systemic aquired resistance. The Plant Cell 3, 1085-1094.

Widmer TL, Laurent N. 2006 - Plant extracts containing caffeic acid and rosmarinic acid inhibit zoospore germination of Phytophthora spp. pathogenic to Theobroma cacao. European Journal of Plant Pathology 115, 377-388. 